\title{
Perencanaan Reed-bed dalam Pengolahan Air Limbah Domestik Menggunakan Tanaman Canna Indica (Studi Kasus: Rusunawa Penjaringan Sari 1 dan 2)
}

\author{
Rinda Meylia Widyasari dan Bieby Voijant Tangahu \\ Jurusan Teknik Lingkungan, Fakultas Teknik Sipil dan Perencanaan, Institut Teknologi Sepuluh \\ Nopember (ITS) \\ Jl. Arief Rahman Hakim, Surabaya 60111 Indonesia \\ e-mail: voijant@enviro.its.ac.id
}

\begin{abstract}
Abstrak-Rusunawa Penjaringan Sari 1 dan 2 merupakan rumah susun sederhana sewa yang terdapat di Surabaya dan terletak di Jalan Penjaringan Sari, Kecamatan Rungkut, Surabaya. Sebagai konsekuensi dari kegiatan yang terdapat di rumah susun maka dihasilkan limbah domestik yang berupa black water dan grey water. Kualitas air limbah domestik yang berasal dari efluen tangki septik dan grey water memiliki konsentrasi BOD $191 \mathrm{mg} / \mathrm{L}$, COD $311 \mathrm{mg} / \mathrm{L}$, dan TSS $127 \mathrm{mg} / \mathrm{L}$. Sedangkan kuantitas air limbahnya sebesar $258 \mathrm{~m}^{3} / \mathrm{hari}$. Berdasarkan Pergub Jatim No 72 Tahun 2013 Baku Mutu Air Limbah Domestik [Permukiman (Real Estate), Rumah Makan (Restoran), Perkantoran, Perniagaan, Apartemen, Perhotelan dan Asrama], kadar polutan di Rusunawa Penjaringan Sari 1 dan 2 masih melampaui baku mutu. Oleh sebab itu diperlukan suatu perencanaan unit pengolahan air limbah domestik dari efluen tangki septik dan grey water di Rusunawa Penjaringan Sari 1 dan 2 sebelum memasuki saluran drainase umum. Pada perencanaan ini digunakan reed-bed tipe sub-surface horizontal flow dengan menggunakan Canna indica (Tanaman kana) dan media gravelly sand. Unit pengolahan air limbah domestik di Rusunawa Penjaringan Sari 1 dan 2 akan dilengkapi dengan bak ekualisasi, reed-bed, dan bak penampung. Berdasarkan kualitas dan kuantitas air limbah di Rusunawa Penjaringan Sari 1 dan 2 direncanakan dimensi dari 2 reed-bed masing-masing yaitu 9 m x $71 \mathrm{~m}$, atau seluas $1278 \mathrm{~m}^{2}$. Hasil perencanaan menunjukkan efisiensi BOD, COD, dan TSS masing-masing sebesar $86 \%, 89 \%$, dan $84 \%$ pada waktu detensi satu hari.
\end{abstract}

Kata Kunci-Air limbah domestik, Canna indica, Reed-bed, Rusunawa.

\section{PENDAHULUAN}

$\mathrm{S}$ EBAGAI kota metropolitan di Jawa Timur, Kota Surabaya telah mengalami pertumbuhan yang sangat pesat dalam berbagai bidang. Begitu pula dengan kenaikan kebutuhan rumah layak huni bagi seluruh masyarakat Kota Surabaya. Oleh karena itu pemerintah membangun rumah susun sederhana sewa sebagai alternatif hunian layak bagi masyarakat berpenghasilan rendah. Namun keberadaan rusunawa membawa beberapa masalah seperti kecenderungan menjadi kumuh dan kondisi sanitasi yang buruk [1].

Salah satu rumah susun sederhana sewa yang terdapat di Surabaya adalah rusunawa Penjaringan Sari 1 dan 2 yang terletak di Jalan Penjaringan Sari, Kecamatan Rungkut, Surabaya. Sebagai konsekuensi dari kegiatan yang terdapat di rumah susun maka dihasilkan limbah domestik yang berupa black water dan grey water. Karakteristik air limbah di Rusunawa Penjaringan Sari I dan II memiliki kandungan BOD $191 \mathrm{mg} / \mathrm{L}$, COD $311 \mathrm{mg} / \mathrm{L}$, dan TSS $127 \mathrm{mg} / \mathrm{L}$. Berdasarkan Pergub Jatim No 72 Tahun 2013 Baku Mutu Air Limbah Domestik (Permukiman (Real Estate), Rumah Makan (Restoran), Perkantoran, Perniagaan, Apartemen, Perhotelan dan Asrama), kadar polutan di Rusunawa Penjaringan Sari 1 dan 2 masih melampaui baku mutu. Berdasarkan Permen PU No 5 Tahun 2007 tentang Pedoman Teknis Pembangunan Rumah Susun Sederhana Bertingkat Tinggi diwajibkan adanya pengolahan terhadap air limbah domestik sebelum dibuang ke saluran drainase umum. Hal ini sejalan dengan UU No 32 Tahun 2009 tentang Perlindungan dan Pengelolaan Lingkungan Hidup yang menekankan pada upaya pencegahan terjadinya pencemaran dan kerusakan lingkungan hidup. Oleh sebab itu diperlukan suatu perencanaan pengelolaan air limbah dari efluen tangki septik dan grey water di Rusunawa Penjaringan Sari 1 dan 2 agar tidak terjadi pencemaran limbah domestik terhadap saluran drainase umum di sekitar rusunawa.

Salah satu jenis pengolahan air limbah domestik yang saat ini sedang dikembangkan adalah dengan prinsip pengolahan biologis menggunakan reed-bed. Reed-bed adalah salah satu alternatif pengolahan biologis yang ekonomis dan mudah dalam pengoperasiannya. Prinsip kerja sistem pengolahan limbah tersebut dengan memanfaatkan simbiosis antara tumbuhan air dengan mikroorganisme dalam media di sekitar sistem perakaran (Rhizosphere) tanaman tersebut.

Pada perencanaan ini akan direncanakan reed-bed tipe $s u b$ surface horizontal flow dengan menggunakan tanaman Canna indica (Tanaman kana). Penggunaan tanaman kana dapat meningkatkan tingkat penyisihan organik hingga 90\% [1]. Pada perencanaan reed-bed ini diharapkan mampu memperbaiki kualitas air limbah yang akan menuju badan air sehingga memenuhi baku mutu yang telah ditetapkan pada Pergub Jawa Timur Nomor 72 Tahun 2013.

\section{METODE PERENCANAAN}

\section{A. Tahap Pengumpulan Data}

Data yang diperlukan dalam perencanaan ini meliputi data primer dan data sekunder. Data primer diperoleh dengan melakukan tinjauan lapangan secara langsung. Sedangkan data sekunder diperoleh melalui dinas yang terkait dan pengelola 
Rusunawa Penjaringan Sari 1 dan 2.

\section{1) Data Primer}

a. Debit air bersih, diperoleh dari data rekening tagihan air unit rusunawa dari masing-masing ketua RT di Rusunawa Penjaringan Sari 1 dan 2. Data penggunaan air bersih yang digunakan adalah data selama 3 bulan terakhir yaitu bulan Januari 2016, Februari 2016, dan Maret 2016.

b. Parameter uji air limbah meliputi BOD, COD, TSS, pH, dan suhu yang akan dianalisis di laboratorium Jurusan Teknik Lingkungan-ITS. Pengambilan sampel air limbah dilakukan pada saat $\mathrm{Q}_{\text {peak }}$ dan dilakukan pengulangan sebanyak tiga kali. $Q_{\text {peak }}$ terjadi ketika debit air limbah berada dalam kondisi puncak yang akan terjadi pada saat jam puncak penggunaan air bersih. Pengambilan sampel pada saat $\mathrm{Q}_{\text {peak }}$ akan dilakukan pada sekitar pukul 08.00 09.00 WIB pada hari Senin. Hal ini didasarkan pada asumsi bahwa pada hari Senin terjadi aktivitas puncak penggunaan air bersih.

c. Jumlah unit dan jumlah penghuni, diperoleh dari data dari UPT Rusunawa Penjaringan Sari dan dari data ketua RT.

d. Luas lahan yang tersedia untuk pembangunan unit pengolahan diperoleh dengan menggunakan google-earth.

2) Data Sekunder

Sedangkan data sekunder yang dibutuhkan adalah peta dan site plan Rusunawa Penjaringan Sari I dan II, dan data presentase removal BOD, COD, dan TSS oleh tanaman Canna indica.

\section{B. Tahap Perencanaan}

Dalam perencanaan reed-bed ini meliputi:

a. Penentuan debit rata-rata penggunaan air bersih dari data rekening pelanggan PDAM di Rusunawa Penjaringan Sari 1 dan 2.

b. Penentuan debit air limbah berdasarkan asumsi $80 \%$ penggunaan air bersih.

c. Penentuan kualitas air limbah yang meliputi parameter BOD, COD, TSS, pH, dan suhu yang dilakukan di Laboratorium Teknik Lingkungan ITS.

d. Penentuan waktu detensi, jenis media, dan kedalaman bak.

e. Perhitungan dimensi reed-bed.

f.Perhitungan Mass Balance dan Water Balance.

\section{HASIL DAN PEMBAHASAN}

\section{A. Data Penghuni Rusunawa Penjaringan Sari 1 dan 2}

Rusunawa Penjaringan Sari 1 dan 2 terletak di Jalan Penjaringan Sari, Kecamatan Rungkut, Surabaya. Rusunawa Penjaringan Sari 1 dan 2 terbagi dalam 6 blok dan memiliki 508 unit. Setiap unitnya diisi oleh $1 \mathrm{KK}$ yang maksimal diisi oleh 4 orang. Rusunawa Penjaringan Sari 1 terdiri dari 220 unit dengan rincian gedung A terdiri dari 74 unit dan gedung $B$ serta gedung $\mathrm{C}$ terdiri dari 73 unit. Sedangkan Rusunawa Penjaringan Sari 2 terdiri 288 unit dengan masing-masing gedung terdapat 96 unit. Pada perencanaan ini akan diasumsikan seluruh unit dihuni oleh 4 orang dimana rusunawa pada kondisi maksimal terisi. Maka jumlah penghuni di Rusunawa Penjaringan Sari 1 dan 2 saat kondisi maksimal adalah 2032 orang.

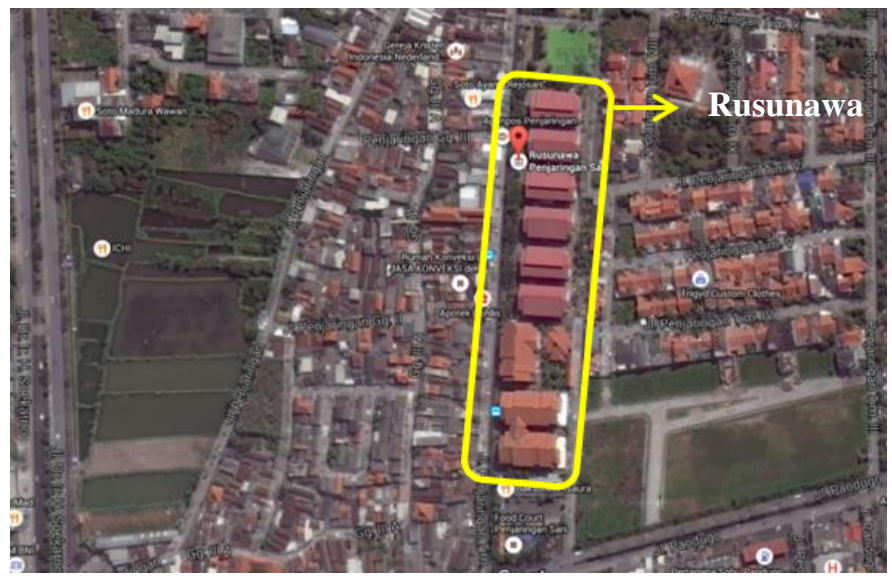

Gambar. 1. Lokasi Rusunawa Penjaringan Sari 1 dan 2

\section{B. Kuantitas Air Limbah Domestik}

Besarnya debit rata-rata air limbah domestik di Rusunawa Penjaringan Sari 1 dan 2 diperoleh dengan mengasumsikan $80 \%$ penggunaan air bersih akan menjadi air limbah. Debit air bersih diperoleh dari data rekening tagihan air bersih di unit Rusunawa Penjaringan Sari 1 dan 2 selama 3 bulan terakhir. Pengambilan data untuk mengetahui debit air bersih rata-rata dilakukan dengan teknik sampling acak menggunakan rumus sebagai berikut [3].

$$
\begin{aligned}
\mathrm{D} & =\frac{B^{2}}{4} \\
\mathrm{n} & =\frac{N(p(1-p))}{(N-1) D+p(1-p)}
\end{aligned}
$$

Keterangan:

n : jumlah sampel

$\mathrm{N} \quad$ : jumlah populasi

$\mathrm{p} \quad$ : proporsi pengambilan sampel

$\mathrm{B} \quad$ : error tolerance

Berdasarkan rumus tersebut diperoleh hasil 96 responden. Jumlah data yang dibutuhkan jika dalam 1 unit rusunawa terdapat 4 orang adalah:

$$
\begin{aligned}
& =96 \text { orang } \div 4 \text { orang } \\
& =24 \text { unit }
\end{aligned}
$$

Hasil perhitungan debit rata-rata air bersih di Rusunawa Penjaringan Sari 1 dan 2 terdapat pada Tabel 1:

Tabel 1.

Kebutuhan Air Bersih Rusunawa Penjaringan Sari 1 dan 2

\begin{tabular}{ccc}
\hline \hline Bulan & $\begin{array}{c}\text { Kebutuhan Air Bersih } \\
\text { Total }\left(\mathrm{m}^{3}\right)\end{array}$ & $\begin{array}{c}\text { Kebutuhan Air Bersih per } \\
\text { Orang }\left(\mathrm{m}^{3} / \text { hari }\right)\end{array}$ \\
\hline Januari & 494 & 5,14 \\
Februari & 444 & 4,63 \\
Maret & 431 & 4,49 \\
Total & $\mathbf{4 5 6}$ & $\mathbf{4 , 7 6}$ \\
\hline \hline
\end{tabular}

Maka, debit air limbah dapat ditentukan sebagai berikut:

$\mathrm{Q}_{\text {(air bersih) }}=4,755 \mathrm{~m}^{3} /$ orang.bulan 


$$
\begin{aligned}
& =0.158 \mathrm{~m}^{3} / \text { orang.hari } \\
& \begin{aligned}
\mathrm{Q}_{\text {(total air bersih) }} & =0.158 \mathrm{~m}^{3} / \text { orang.hari } \times 2032 \text { orang } \\
& =322,04 \mathrm{~m}^{3} / \text { hari }
\end{aligned} \\
& \begin{aligned}
\mathrm{Q}_{\text {(air limbah) }}= & 80 \% \times \mathrm{Q}_{\text {(total air bersih) }} \\
= & 80 \% \times 322,04 \mathrm{~m}^{3} / \text { hari } \\
= & 257,63 \mathrm{~m}^{3} / \mathrm{hari} \approx 258 \mathrm{~m}^{3} / \text { hari }
\end{aligned}
\end{aligned}
$$

\section{Kualitas Air Limbah Domestik}

Berdasarkan hasil analisis laboratorium terhadap kualitas air limbah domestik yang berasal dari grey water dan efluen tangki septik di Rusunawa Penjaringan Sari 1 dan 2 diperoleh hasil pada Tabel 2 berikut:

Tabel 2.

Kualitas Air Limbah Rusunawa Penjaringan Sari 1 dan 2

\begin{tabular}{cccc}
\hline \hline \multirow{2}{*}{ Parameter } & Analisis 1 & Analisis 2 & Analisis 3 \\
\hline BOD & $195 \mathrm{mg} / \mathrm{L}$ & $184 \mathrm{mg} / \mathrm{L}$ & $194 \mathrm{mg} / \mathrm{L}$ \\
COD & $282 \mathrm{mg} / \mathrm{L}$ & $317 \mathrm{mg} / \mathrm{L}$ & $336 \mathrm{mg} / \mathrm{L}$ \\
TSS & $100 \mathrm{mg} / \mathrm{L}$ & $120 \mathrm{mg} / \mathrm{L}$ & $160 \mathrm{mg} / \mathrm{L}$ \\
pH & 6,53 & 6,89 & 7,31 \\
Suhu & $29^{\circ} \mathrm{C}$ & $29^{\circ} \mathrm{C}$ & $29^{\circ} \mathrm{C}$ \\
BOD/COD & 0,69 & 0,58 & 0,58 \\
\hline \hline
\end{tabular}

Sehingga rata-rata kualitas air limbah di Rusunawa Penjaringan Sari 1 dan 2 untuk setiap parameter yaitu.

$\mathrm{BOD}_{5}=191 \mathrm{mg} / \mathrm{L}$

$\mathrm{COD}=311 \mathrm{mg} / \mathrm{L}$

$\mathrm{TSS}=127 \mathrm{mg} / \mathrm{L}$

$\mathrm{pH} \quad=6,91$

Suhu $=29^{\circ} \mathrm{C}$

\section{Perhitungan Reed-bed}

Perencanaan unit pengolahan air limbah domestik di meliputi bak ekualisasi, pompa, reed-bed tipe subsurface flow, dan bak penampung.

1. Bak ekualisasi

Bak ekualisasi berfungsi untuk mengatur debit air limbah yang akan diolah dan menyeragamkan konsentrasi zat pencemar sehingga proses pengolahan dapat berjalan secara stabil. Selain itu dapat juga dijadikan sebagai bak aerasi awal pada saat terjadi beban secara tiba-tiba (shock load). Bak ekualisasi yang direncanakan berbentuk persegi panjang dengan perhitungan dimensi sebagai berikut. Adapun perhitungan bak ekualisasi menggunakan faktor pemakaian air bersih sebagai pembagian debit tiap jam dalam 1 hari, faktor pemakaian maksimum sebesar 1,5 dan faktor pemakaian minimum 0,3. Debit rata-rata air bersih sebesar $13,42 \mathrm{~m}^{3} / \mathrm{jam}$. Fluktuasi debit air limbah dapat dihitung dengan mengasumsikan $80 \%$ air bersih akan menjadi air limbah yaitu dalam Tabel 3.

Tabel 3 .

Fluktuasi Air Limbah

\begin{tabular}{ccccc}
\hline \hline Periode & $\begin{array}{c}\text { Faktor } \\
\text { Pemakaian } \\
\text { Air }\end{array}$ & $\begin{array}{c}\text { Pemakaian } \\
\text { Air Bersih } \\
\left(\mathrm{m}^{3} / \mathrm{jam}\right)\end{array}$ & $\begin{array}{c}\text { Air Limbah } \\
\left(\mathrm{m}^{3} / \mathrm{jam}\right)\end{array}$ & $\begin{array}{c}\text { Selisih } \\
\left(\mathrm{m}^{3} / \mathrm{jam}\right)\end{array}$ \\
\hline $00.00-01.00$ & 0,3 & 4,0 & 3,2 & 7,6 \\
$01.00-02.00$ & 0,1 & 1,3 & 1,1 & 9,7 \\
$02.00-03.00$ & 0,1 & 1,3 & 1,1 & $\mathbf{9 , 7}$ \\
$03.00-04.00$ & 0,3 & 4,0 & 3,2 & 7,6 \\
$04.00-0.500$ & 0,5 & 6,7 & 5,4 & 5,4 \\
\hline \hline
\end{tabular}

Tabel 3 (Lanjutan)

Fluktuasi Air Limbah

\begin{tabular}{ccccc}
\hline \hline Periode & $\begin{array}{c}\text { Faktor } \\
\text { Pemakaian } \\
\text { Air }\end{array}$ & $\begin{array}{c}\text { Pemakaian } \\
\text { Air Bersih } \\
\left(\mathrm{m}^{3} / \text { jam }\right)\end{array}$ & $\begin{array}{c}\text { Air Limbah } \\
\left(\mathrm{m}^{3} / \text { jam }\right)\end{array}$ & $\begin{array}{c}\text { Selisih } \\
\left(\mathrm{m}^{3} / \text { jam }\right)\end{array}$ \\
\hline $05.00-06.00$ & 1,4 & 18,8 & 15,0 & $-4,2$ \\
$06.00-07.00$ & 1,6 & 21,5 & 17,2 & $-6,4$ \\
$07.00-08.00$ & 1,8 & 24,2 & 19,3 & $-8,5$ \\
$08.00-09.00$ & 1,0 & 13,4 & 10,7 & 0,0 \\
$09.00-10.00$ & 0,8 & 10,7 & 8,6 & 2,2 \\
$10.00-11.00$ & 0,8 & 10,7 & 8,6 & 2,2 \\
$11.00-12.00$ & 1,1 & 14,8 & 11,8 & $-1,0$ \\
$12.00-13.00$ & 1,1 & 14,8 & 11,8 & $-1,0$ \\
$13.00-14.00$ & 1,0 & 13,4 & 10,7 & 0,0 \\
$14.00-15.00$ & 0,8 & 10,7 & 8,6 & 2,2 \\
$15.00-16.00$ & 1,2 & 16,1 & 12,9 & $-2,1$ \\
$16.00-17.00$ & 1,6 & 21,5 & 17,2 & $-6,4$ \\
$17.00-18.00$ & 1,8 & 24,2 & 19,3 & $-8,5$ \\
$18.00-19.00$ & 1,8 & 24,2 & 19,3 & $-\mathbf{8 , 5}$ \\
$19.00-20.00$ & 1,5 & 20,1 & 16,1 & $-5,3$ \\
$20.00-21.00$ & 1,2 & 16,1 & 12,9 & $-2,1$ \\
$21.00-22.00$ & 1,0 & 13,4 & 10,7 & 0,0 \\
$22.00-23.00$ & 0,8 & 10,7 & 8,6 & 2,2 \\
$23.00-00.00$ & 0,5 & 6,7 & 5,4 & 5,4 \\
Total & & $\mathbf{3 2 3}$ & $\mathbf{2 5 8}$ & \\
\hline \hline
\end{tabular}

Dari tabel diatas diambil nilai tertinggi $(9,7)$ dan terendah ($8,5)$. Nilai tertinggi merupakan volume maksimal perhari yang dihasilkan pada waktu tertentu. Nilai terendah merupakan volume yang tidak tertampung pada waktu tertentu. Maka perhitungan volume bak ekualisasi sebagai berikut :

Volume $(\mathrm{v})=$ surplus maksimum - defisit minimum.

Direncanakan:

$$
=9,7-(-8,5)=18,2 \mathrm{~m}^{3}
$$

$$
\mathrm{P}: \mathrm{L} \quad=1: 1
$$

Kedalaman $(\mathrm{h})=2 \mathrm{~m}$, maka:

$$
\text { As }=\frac{v}{h}=\frac{18,2}{2}=9,1 \mathrm{~m}^{2}
$$

Dimensi bak ekualisasi

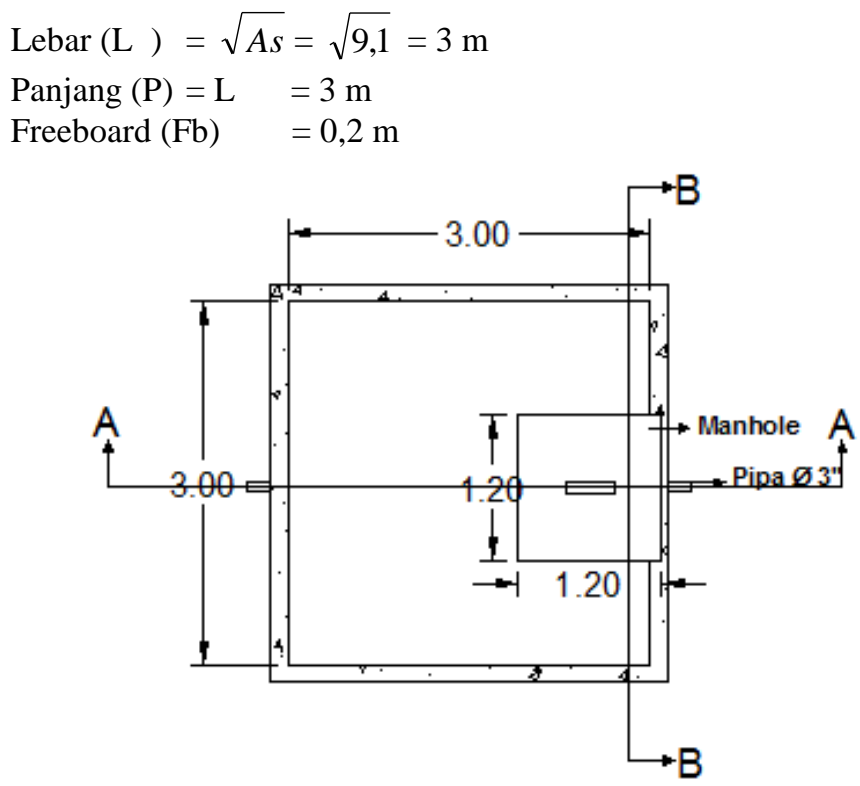

Gambar. 2. Bak Ekualisasi 
a. Kebutuhan Pompa

Pada perencanaan ini akan digunakan pompa submersible untuk mengalirkan air dari bak ekualisasi menuju reed-bed. Berikut adalah perhitungan head pompa.

- Head Total Pompa

Perhitungan head total pompa diperoleh dengan menggunakan rumus 2.12 :

$$
\mathrm{H}=\mathrm{H}_{\mathrm{s}}+\Delta \mathrm{H}_{\mathrm{p}}+\mathrm{H}_{\mathrm{a}}+\mathrm{H}_{\mathrm{l}}+\frac{v^{2}}{2 g}
$$

Head static $(\mathrm{Hs})$

Head static adalah perbedaan tinggi muka air dan sisi isap pompa. Head static yang direncanakan, yaitu:

$\mathrm{Hs}=1,9 \mathrm{~m}$

$>$ Pressure head $(\Delta \mathrm{Hp})$

Pressure head yaitu perbedaan head yang bekerja pada kedua permukaan air. Pada perencanaan ini tekanan dianggap sama $(\Delta \mathrm{Hp}=0)$.

$>$ Head mayor

Head mayor adalah kerugian head yang terjadi di sepanjang pipa.

$$
\begin{aligned}
\mathrm{Hf} & =\left[\frac{\mathrm{Q}}{0,2785 \times \mathrm{C} \times \mathrm{D}^{2,63}}\right]^{1,85} \times L \\
& =\left[\frac{0,00298}{0,2785 \times 130 \times 0,0796^{2,63}}\right]^{1,85} \times 56 \\
& =0,35 \mathrm{~m}
\end{aligned}
$$

\section{Head Minor}

Head minor adalah kerugian head yang disebabkan aksesoris pada pipa. Pada perencanaan ini aksesoris pipa yang digunakan adalah knee $90^{\circ}$ sebanyak 4 buah, dan percabangan sebanyak 3 buah.

Head minor akibat knee $90^{\circ}$, nilai $\mathrm{k}=1,5$

$$
\begin{aligned}
\mathrm{Hf} & =\mathrm{n}\left[k \frac{v^{2}}{2 g}\right] \\
& =4\left[1,5 \frac{0,6^{2}}{2 \times 9,81}\right]=0,11 \mathrm{~m}
\end{aligned}
$$

Head minor akibat percabangan, nilai $\mathrm{k}=0,96$

Hf $=6\left[0,96 \frac{0,6^{2}}{2 \times 9,81}\right]=0,11 \mathrm{~m}$

Head minor total

$$
\begin{aligned}
\mathrm{Hf} & =0,11 \mathrm{~m}+0,11 \mathrm{~m} \\
& =0,22 \mathrm{~m}
\end{aligned}
$$

Head total pompa

Hf $=1,9 m+0+0,35 m+0,22 m+0,018$

$$
=2,488 \mathrm{~m}
$$

- Headloss pada reed-bed

Berdasarkan Hukum Darcy headloss dari reed-bed dapat dihitung dengan menggunakan persamaan berikut [4].

$$
\mathrm{W}^{2}=\frac{Q \times A s}{K \times D w \times h f}
$$

sehingga besarnya headloss adalah:

$$
\begin{aligned}
\mathrm{hf} & =\frac{Q \times A s}{K \times D w \times W^{2}} \\
& =\frac{289 \times 1278}{5000 \times 0,6 \times 9^{2}}=1,48 \mathrm{~m}
\end{aligned}
$$

- Besarnya total headloss keseluruhan adalah:

$$
\begin{aligned}
& =2,488 \mathrm{~m}+1,48 \mathrm{~m} \\
& =3,968 \mathrm{~m} \approx 4,0 \mathrm{~m}
\end{aligned}
$$

Dari perhitungan tersebut diketahui head total pompa yaitu 4,0 $\mathrm{m}$ dan besarnya debit yaitu $258 \mathrm{~m}^{3} /$ hari atau $3 \mathrm{~L} / \mathrm{s}$ maka jenis pompa yang akan digunakan dapat ditentukan. Pada perencanaan ini digunakan pompa merk Grundfos dan pemilihan jenis pompa dilakukan menggunakan aplikasi WinCAPS. Berikut adalah hasil dari sizing pompa menggunakan WinCAPS:

Jenis pompa: Submersible pump

Merk : Grundfos

Tipe : SEV.80.80.11.A.4.50D

\section{Reed-bed}

Pada perencanaan ini sistem pengaliran reed-bed adalah subsurface flow (SFS). Desain sistem SFS yang direncanakan berjumlah dua unit agar terjadi aliran yang intermiten dan mempermudah maintenance. Berikut perhitungan perencanaan dari reed-bed:

Debit $(\mathrm{Q}) \quad=258 \mathrm{~m}^{3} / \mathrm{hari}$

Jumlah unit $\quad=2$ unit

Debit tiap unit $=\frac{258 \mathrm{~m}^{3} / \text { hari }}{2 \text { unit }}$

$$
=129 \mathrm{~m}^{3} / \text { hari }
$$

BOD influen $(\mathrm{Co})=191 \mathrm{mg} / \mathrm{L}$

BOD efluen $(\mathrm{Ce}) \quad=30 \mathrm{mg} / \mathrm{L}$

Suhu (T) $\quad=29^{\circ} \mathrm{C}$

Tipe vegetasi = Canna indica

Media = Gravelly sand

Slope $(\mathrm{s}) \quad=0,5 \%$ (flat bottom)

- Kedalaman

Kedalaman unit pengolahan reed-bed ditentukan berdasarkan jenis vegetasi yang akan digunakan pada sistem. Pada perencanaan ini jenis vegetasi yang digunakan adalah tanaman Canna indica yang memiliki kemampuan penetrasi rizhoma hingga 10-60 cm. Oleh sebab itu kedalaman reedbed dalam perencanaan ini adalah $60 \mathrm{~cm}(0,6 \mathrm{~m})$.

- Nilai $\alpha, \mathrm{k}_{\mathrm{s}}$, dan $\mathrm{K}_{20}$

Nilai $\alpha, \mathrm{k}_{\mathrm{s}}$, dan $\mathrm{K}_{20}$ menyesuaikan pada media yang akan digunakan pada sistem. Pada perencanaan ini digunakan media berupa gravelly sand. Nilai $\alpha, \mathrm{k}_{\mathrm{s}}$, dan $\mathrm{K}_{20}$ untuk media gravelly sand adalah:

$\alpha=0,35$

$\mathrm{k}_{\mathrm{s}}=5000 \mathrm{~m}^{3} / \mathrm{m}^{2}$.hari

$\mathrm{K}_{20}=0,86$

- Nilai $K_{T}$ 
Besarnya nilai $\mathrm{K}_{\mathrm{T}}$ dipengaruhi oleh temperatur air dengan menggunakan persamaan sebagai berikut:

$$
\begin{aligned}
& \mathrm{K}_{\mathrm{T}}=\mathrm{K}_{20}(1,1)^{(\mathrm{T}-20)} \\
& \mathrm{K}_{29}=0.86 \times(1,1)^{(29-20)} \\
& \mathrm{K}_{29}=2,03 \text { hari }^{-1}
\end{aligned}
$$

- Waktu detensi pore-space (td)

Definisi dari waktu detensi pore-space (td) adalah waktu detensi teoritis berdasarkan porositas dari media [5].

$$
\begin{aligned}
\operatorname{td} & =-\frac{\ln \frac{C e}{C o}}{K t} \\
& =-\frac{\ln \frac{30}{191}}{2,03}=0,913 \text { hari } \approx 1 \text { hari }
\end{aligned}
$$

- Cross sectional area (Ac)

Ac diperoleh dengan menggunakan perhitungan berikut:

$$
\begin{aligned}
\text { Ac } & =\frac{Q}{K s \times S} \\
& =\frac{129}{5000 \times 0,005}=5,16 \mathrm{~m}^{2}
\end{aligned}
$$

- Lebar (W)

Lebar dari reed-bed diperoleh dengan perhitungan berikut:

$$
\begin{aligned}
\mathrm{W} & =\frac{A c}{d} \\
& =\frac{5,16}{0,6}=9 \mathrm{~m}
\end{aligned}
$$

- Panjang (L)

Panjang dari reed-bed diperoleh dengan perhitungan berikut:

$$
\begin{aligned}
\mathrm{L} & =\frac{t^{\prime} \times Q}{W \times d \times a} \\
& =\frac{1 \times 129}{9 \times 0,6 \times 0,35}=71 \mathrm{~m}
\end{aligned}
$$

- Luas Permukaan

Luas permukaan dari reed-bed diperoleh dari perhitungan:

$\mathrm{As}=\mathrm{L} \times \mathrm{W}$

$$
=9 \mathrm{~m} \times 71 \mathrm{~m}=614 \mathrm{~m}^{2}
$$

Perbandingan $\mathrm{p}: 1=1: 8,3$

- Hydraulic Loading Rate (Lw)

Lw didefinisikan sebagai jumlah volume dari air limbah per hari dibanding luasan area yang digunakan untuk pengolahan limbah Perhitungan Lw mengacu pada perhitungan berikut:

$$
\begin{aligned}
\mathrm{Lw} & =\frac{Q}{A s} \\
& =\frac{129}{614}=0,21 \mathrm{~m}^{3} / \mathrm{m}^{2} \cdot \text { hari }=21 \mathrm{~cm} / \text { hari }
\end{aligned}
$$

HLR pada saat pengurasan :

Lw $=\frac{258}{614}=0,42 \mathrm{~m}^{3} / \mathrm{m}^{2} \cdot$ hari $=42 \mathrm{~cm} /$ hari $(\mathrm{OK})$
- BOD Loading Rate

Perhitungan $\mathrm{BOD}_{\mathrm{L}}$ mengacu pada persamaan berikut:

$$
\begin{aligned}
\text { BOD }_{\mathrm{L}} & =\frac{Q \times C}{A} \\
& =\frac{129 \times 191}{614}=46,13 \mathrm{~kg} / \mathrm{m}^{2} \text {.hari }
\end{aligned}
$$

BOD loading rate pada saat pengurasan :

$\mathrm{BOD}_{\mathrm{L}}=\frac{258 \times 191}{614}=80,25 \mathrm{~kg} / \mathrm{m}^{2} \cdot \operatorname{hari}(\mathrm{OK})$

- Penyisihan TSS

Penyisihan TSS untuk sistem SFS dapat menggunakan persamaan berikut:

$\mathrm{Ce}=\mathrm{Co}[0,1058+0,0011(\mathrm{Lw})]$

Dimana :

$$
\begin{aligned}
& \mathrm{Ce}=\text { efluen TSS }(\mathrm{mg} / \mathrm{L}) \\
& \mathrm{Co} \quad=\text { influen TSS }(\mathrm{mg} / \mathrm{L}) \\
& \mathrm{Lw}=\text { hydraulic loading rate }(\mathrm{cm} / \mathrm{hari}) \\
& \begin{aligned}
\mathrm{Maka}, & \\
\mathrm{Ce} & =\mathrm{Co}[0,1058+0,0011(\mathrm{Lw})] \\
& =126,667[0,1058+0,0011(22,96)] \\
& =16,6 \mathrm{mg} / \mathrm{L}
\end{aligned}
\end{aligned}
$$

Nilai Ce TSS sebesar 16,6 mg/L telah memenuhi syarat baku mutu Pergub Jatim No 72 Tahun 2013 yaitu 50 mg/L.

- Penyisihan BOD

Besarnya efluen yang dihasilkan dari proses pengolahan pada reed-bed dapat dihitung dengan menggunakan persamaan berikut untuk jenis reaktor non recycle ratio 1:1[6], yaitu :

$0=\operatorname{Qr}(\mathrm{Cn})+(1 / \mathrm{n} \cdot \mathrm{Q})(\mathrm{Co})-(\mathrm{Qr}+(1 / \mathrm{n} \cdot \mathrm{Q})(\mathrm{Ce}))+$ $\left(\mathrm{K}_{\mathrm{T}}\right)(\mathrm{Ce}) \mathrm{V}$

Keterangan :

$\mathrm{Qr}=\mathrm{Q}$ recycle (karena non recycle, maka $\mathrm{Qr}=0$ ), $\mathrm{m}^{3} / \mathrm{hari}$

$\mathrm{Cn}=$ konsentrasi BOD efluen dari reaktor, $\mathrm{mg} / \mathrm{L}$

$\mathrm{N}=$ jumlah kolam wetland, unit

$\mathrm{Q}=$ debit aliran air pada saluran, $\mathrm{m}^{3} /$ hari

$\mathrm{Co}=$ konsentrasi BOD influen, $\mathrm{mg} / \mathrm{L}$

$\mathrm{Ce}=$ konsentrasi BOD efluen yang diharapkan dari keseluruhan reaktor, $\mathrm{mg} / \mathrm{L}$

$\mathrm{K}_{\mathrm{T}}=$ tetapan orde pertama dari rate-constant

$\mathrm{V}=$ volume tiap reaktor, $\mathrm{m}^{3}$

$$
\begin{aligned}
& \mathrm{Ce}=\frac{(Q r)(c n)+1 / n(Q)(C O)}{(Q r+(1 / n(Q))+(K t)(V)} \\
& =\frac{0+1 / 1(129)(191)}{(0+(1 / 1(129))+(2,0 a))(269,57)}=26,3 \mathrm{mg} / \mathrm{L}
\end{aligned}
$$

- Perhitungan Efisiensi

Efisiensi penyisihan dari parameter BOD dan TSS dapat dihitung sebagai berikut:

$$
\begin{aligned}
\text { BOD Eff } & =\frac{C o-C e}{C e} \times 100 \% \\
& =\frac{191-26,3}{26,3} \times 100 \%=86 \% \\
\text { TSS Eff } & =\frac{126,7-16,7}{126,7} \times 100 \%=87 \%
\end{aligned}
$$


Sedangkan untuk efisiensi dari parameter COD akan mengacu pada literatur yaitu dengan rata-rata 89\% [7]

- Kebutuhan tanaman Canna Indica pada reed-bed

Banyaknya tanaman kana yang ideal untuk ditanam dalam 1 $\mathrm{m}^{2}$ adalah sekitar 4-5 batang. Jika menggunakan asumsi $1 \mathrm{~m}^{2}$ ditanami dengan 4 batang tanaman, maka kebutuhan total tanaman di reed-bed adalah:

Kebutuhan tanaman = Luas $\mathrm{x} 4$ batang

$$
=1278 \mathrm{~m}^{2} \times 4 \text { batang }=5112 \text { batang }
$$

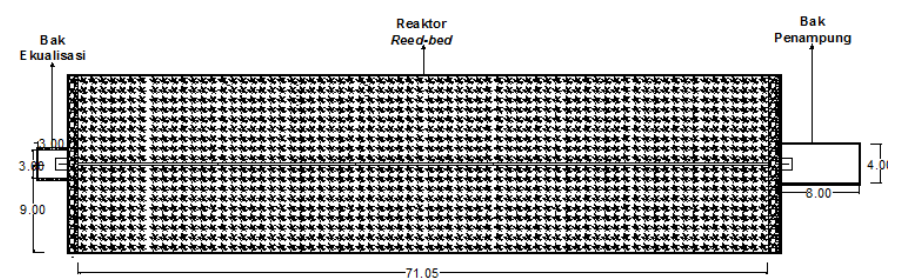

Gambar. 3. Reed bed

\section{Bak Penampung}

Bak penampung difungsikan untuk menampung air hasil olahan dari reed-bed sebelum dibuang menuju badan air. Bak penampung ini nantinya juga dimanfaatkan untuk tendon air siram tanaman.

Direncanakan:

Waktu detensi $(\mathrm{td})=6 \mathrm{jam}$

Debit $(\mathrm{Q})=258 \mathrm{~m}^{3} / \mathrm{hari}$

$$
=10.75 \mathrm{~m}^{3} / \mathrm{jam}
$$

$$
\mathrm{P}: \mathrm{L} \quad=2: 1
$$

Kedalaman $(\mathrm{h}) \quad=2 \mathrm{~m}$

Volume $=\operatorname{td} \times \mathrm{Q}$

$$
\begin{aligned}
& =6 \mathrm{jam} \times 10.75 \mathrm{~m}^{3} / \mathrm{jam} \\
& =64,5 \mathrm{~m}^{3}
\end{aligned}
$$

Dimensi bak penampung

$$
\begin{aligned}
\operatorname{Lebar}(\mathrm{L}) & =\sqrt{\frac{V}{p \times l \times h}} \\
& =\sqrt{\frac{64,5}{2 l \times l \times 2}}=4 \mathrm{~m}
\end{aligned}
$$

Panjang $(\mathrm{P})=2 \mathrm{~L}=8 \mathrm{~m}$

Freeboard $(\mathrm{Fb})=0,2 \mathrm{~m}$

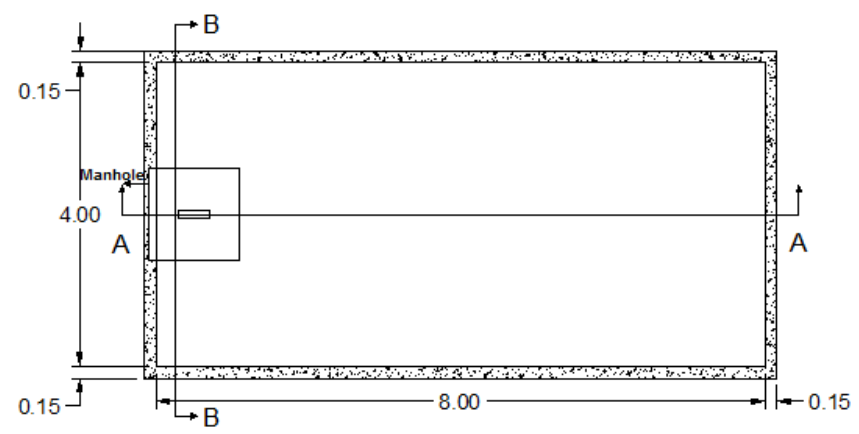

[1]

Gambar. 4. Bak Penampung

\section{KESIMPULAN/RINGKASAN}

Pada perencanaan ini yang digunakan adalah jenis subsurface flow dengan menggunakan tanaman Canna indica dan media gravelly sand. Diperoleh dimensi dari 2 reed-bed masing-masing yaitu $9 \mathrm{~m} \times 71 \mathrm{~m}$, atau seluas $1278 \mathrm{~m}^{2}$.

\section{UCAPAN TERIMA KASIH}

Terima kasih penulis ucapkan kepada Dinas Pertanahan dan Bangunan Kota Surabaya dan Pengurus UPT Rusunawa Penjaringan Sari 1 dan 2 serta Ketua RT 01 - RT 06, RW 07 Rusunawa Penjaringan Sari 1 dan 2 atas fasilitasnya sehingga penelitian ini dapat terlaksana.

\section{DAFTAR PUSTAKA}

[1] N. Hartatik, S. Setijanti, Purwanita. 2010. Peningkatan Kualitas hidup penghuni di Rusunawa Urip Sumohardjo pasca-Redevelopment. Seminar Nasional Perumahan Permukiman dalam Pembangunan Kota Surabaya Tahun 2010

[2] V. Arunbabu, S. Sruthy., I. Anthony, E. V. Ramasamy. 2015. Sustainable Grey Water Management With Axonopus Compressus (Broadleaf Carpet Grass) Planted in Subsurface Flow Constructed Wetland. Journal of Water Process Engineering. Vol. 7. Page 163-170

[3] D. Purhadi, Susilaningrum. 2002. Teknik Sampling. Jurusan Statistika Fakultas Matematika dan Ilmu Pengetahuan Alam-ITS. Surabaya.

[4] J. Miller. 2007. Constructed Wetlands Technology Assessment and Design Guidance. Iowa Department of Natural Resources

[5] Metcalf and Eddy. 2014. Waste Water Engineering, Collection and Pumping of Waste Water. Mc Graw Hill Book Company. New York.

[6] R. Crites, dan G. Tchobanoglous. 2003. Small and Desentralized Wastewater Management Systems, McGraw-Hill Book Company. Singapore.

[7] D. Ariani. 2010. Perencanaan Subsurface Flow Constructed Wetland Dalam Pengolahan Effluen Tangki Septik pada Daerah Air Tanah Dangkal (Studi Kasus: Perumahan Istana Bestari Kota Pasuruan). Tugas Akhir. Teknik Lingkungan FTSP-ITS. Surabaya 